\title{
Post-Harvest Practices, Constraints and Opportunities Along Cassava Value Chain in Kenya
}

\author{
GEORGE OOKO ABONG'*1, SOLOMON SHIBAIRO', ELIZABETH WANJEKECHE², \\ JOSHUA OGENDO ${ }^{3}$, TOM WAMBUA ${ }^{3}$, PETER LAMUKA ${ }^{1}$, PETER ARAMA ${ }^{5}$, \\ MICHAEL OKOTH ${ }^{1}$, RICHARD MULWA ${ }^{3}$, MARGARET KAMIDI ${ }^{2}$, \\ ZADOC MCOSORE ${ }^{2}$ and CHRISTINE KATAMA MASHA ${ }^{4}$
}

\author{
${ }^{1}$ University of Nairobi, PO Box 29053-00625, Nairobi. \\ ${ }^{2}$ Kenya Agricultural and Livestock Research Organization (KALRO), P.O. Box 450 Kitale \\ ${ }^{3}$ Egerton University, P.O. Box 536-20115 Egerton, Kenya. \\ ${ }^{4}$ Industrial Crops Research Institute, P.O.Box 16-80109, Mtwapa, Kenya. \\ ${ }^{5}$ Rongo University College, P.O. Box 103-40404, Rongo, Kenya.
}

http://dx.doi.org/10.12944/CRNFSJ.4.2.05

(Received: July 20, 2016; Accepted: August 17, 2016)

\begin{abstract}
Despite its great potential as a food, feed and for industrial application, its processing and marketing remains economically unexploited. A cross-sectional baseline survey was undertaken in Western (Migori and Busia) and Coastal (Kilifi and Kwale) regions of Kenya between March 2013 and February 2014 using structured questionnaires to assess the post-harvest practices, opportunities and constraints in cassava processing. Results indicate that cassava processing is predominantly $(58 \%)$ a women affair, males accounting for $42 \%$ with modal processors age being 32 years. Flour was the most common processed cassava product in the Coast (33\%) while dried chips was highly produced in Migori and Busia in equal proportion of $43 \%$. Other important products included cassava crisps and composite flour. Coast region had a greater diversity of products which are none existent in other regions. Most of the processing across the regions are small scale with workers mostly being the owners and activities take place in open yards with majority of these being in Busia (85 $\%)$ followed by Migori (67\%) and Coast region (57\%). Constraints during cassava processing were ranked in the following order: irregular and inadequate supply coupled with low seasonal demand for cassava and cassava products; high perishability of cassava roots; lack of value addition and processing tools; poor group dynamics, cohesion and management structure; lack of capacity building in production and processing technologies. There is very limited value addition to cassava in the study regions and hence the need to develop innovative technologies as well as new domestic and industrial products. Consumer sensitization and awareness on utilization of cassava and cassava products may be key to its promotion.
\end{abstract}

Keywords: cassava post-harvest practices, Value addition, constraints, opportunities

\section{INTRODUCTION}

Cassava (Manihot esculenta Crantz) is an important food crop in a number of communities in sub-Sahara Africa and serves as a primary carbohydrate source in their diets. Its contribution to food security and incomes for rural communities in Sub-Saharan Africa is well known ${ }^{1,2,3}$. Over the last few years, there has been mounting recognition of the contribution that cassava can make towards improving food security, incomes and generating employment opportunities in the rural sector ${ }^{4}$.

Several post-harvest problems have, however, limited effective commercialization of the crop. Fresh cassava roots have a very short shelf-life of less than 72 hours after harvest and post-harvest losses of more than $23 \%$ for freshly harvested roots 
have been reported. Consequently cassava roots need to be processed to reduce these losses. The crop is used in diverse forms such as fresh root boiled and eaten as a snack or roots prepared into crisps or dried chips. Dried cassava chips are milled into flour to make stiff porridge known as ugali and common porridge. The end products tend to be of low quality thus creating a need for improved processing into more stable products such as fermented and non-fermented flours, high quality sun dried chips, starches and culinary products 4, 5, 6, 7, 8 . Processing does not only improve shelf life but also reduces bulkiness, diversify products and enhance acceptability and marketability. The roots also have high starch content but deficient in other essential nutrients ${ }^{9}$, while containing varying amounts of cyanide which is toxic to both humans and animals. Processing eliminates or reduces cyanogenic compounds to a safe level set by World Health Organization (WHO) at 10ppm ${ }^{10}$.

Cassava has potential to be processed into a number of products through value addition. Many cassava-based products have been developed and technologies disseminated to farming communities in the region. Despite these efforts, numerous constraints such as scarce capital resources in rural areas, limited knowledge about market characteristics and requirements as well as limited access to markets have been cited ${ }^{11}$. The current survey sought to assess post-harvest activities and constraints as well as opportunities in common cassava growing regions of Coastal and Western regions of Kenya.

\section{MATERIALS AND METHODS}

\section{Study areas and sampling}

A cross-sectional survey along the cassava value was undertaken at the Coastal (Kilifi and Kwale Counties), and Western Kenya (Busia and Migori Counties) between March 2013 and February 2014. For the purpose of this article, Kilifi and Kwale were pooled and hence considered as Coast region. These areas were purposively selected due to large number of cassava farmers, processors and consumers known to exist. Semi-structured questionnaires were used to assess the production and post-harvest practices such as handling and storage methods, range of products, packaging and marketing outlets. A total of 63 processors were exhaustively sampled and face to face interviews conducted during the study following an initial pre-test that was carried out for any required adjustments.

\section{Data analysis}

Data was analyzed using Statistical Package for Social Scientists (SPSS) version sixteen. Means and frequencies were used to summarize acquired data on socio-demographic information as well as post-harvest handling, different products and consumption indices. Chi-square analysis was performed to check for relationships between education level, age and gender preservation

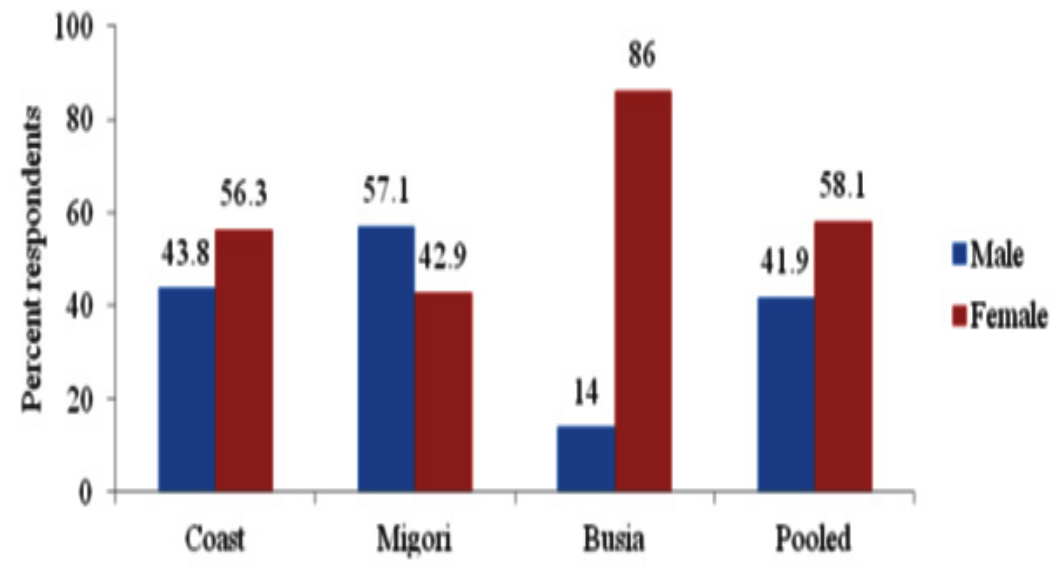

Fig. 1: Gender distribution among cassava processors in Coast, Migori and Busia 
methods, waste management, source of information, choice of variety, treatment after storage and services offered by processors.

\section{RESULTS AND DISCUSSION}

\section{General processors profile}

Out of the 63 processors, $42 \%$ were males while $58 \%$ were females. This distribution differed slightly with regions: more females than males were processing in Coast and Busia while Migori had higher number of males (Figure 1). Busia had exceptionally higher number of females than males. This observed scenario may be attributed to the fact that processing is largely village/domestic type and most of the tools or equipment currently used is biased towards females.

The age of processors ranged from 16 to 61 years with mean and mode of 38 and 32 years,

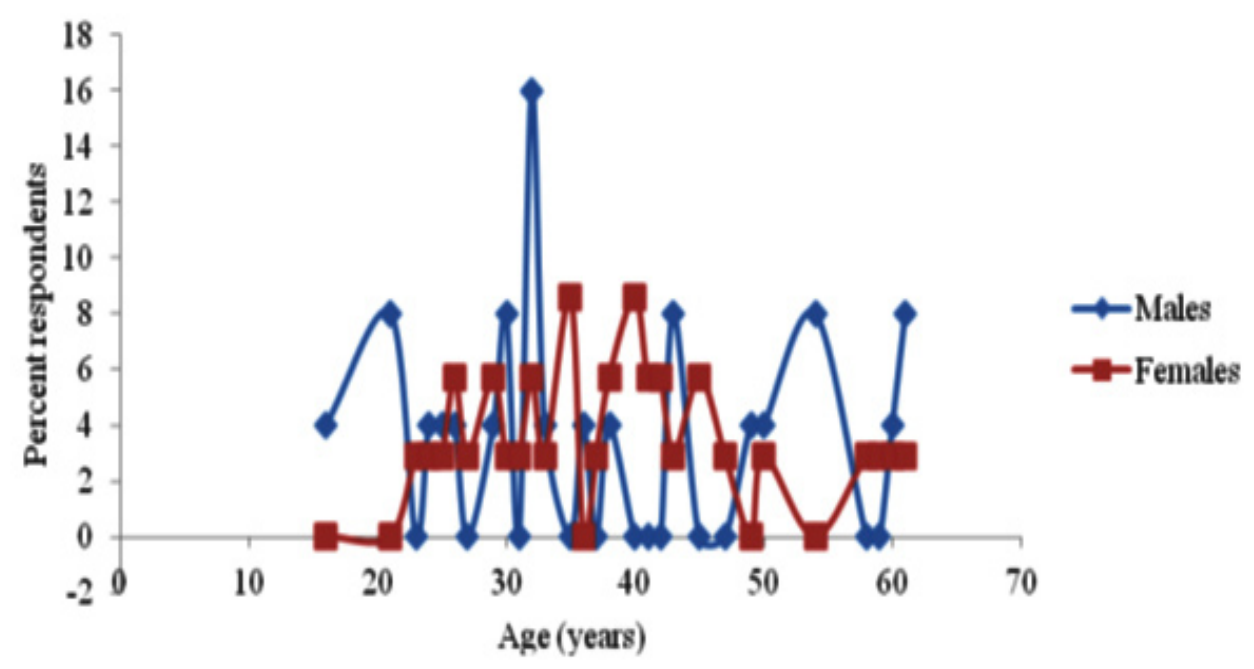

Fig. 2: Age by gender of cassava processors in Coast, Migori and Busia of Kenya

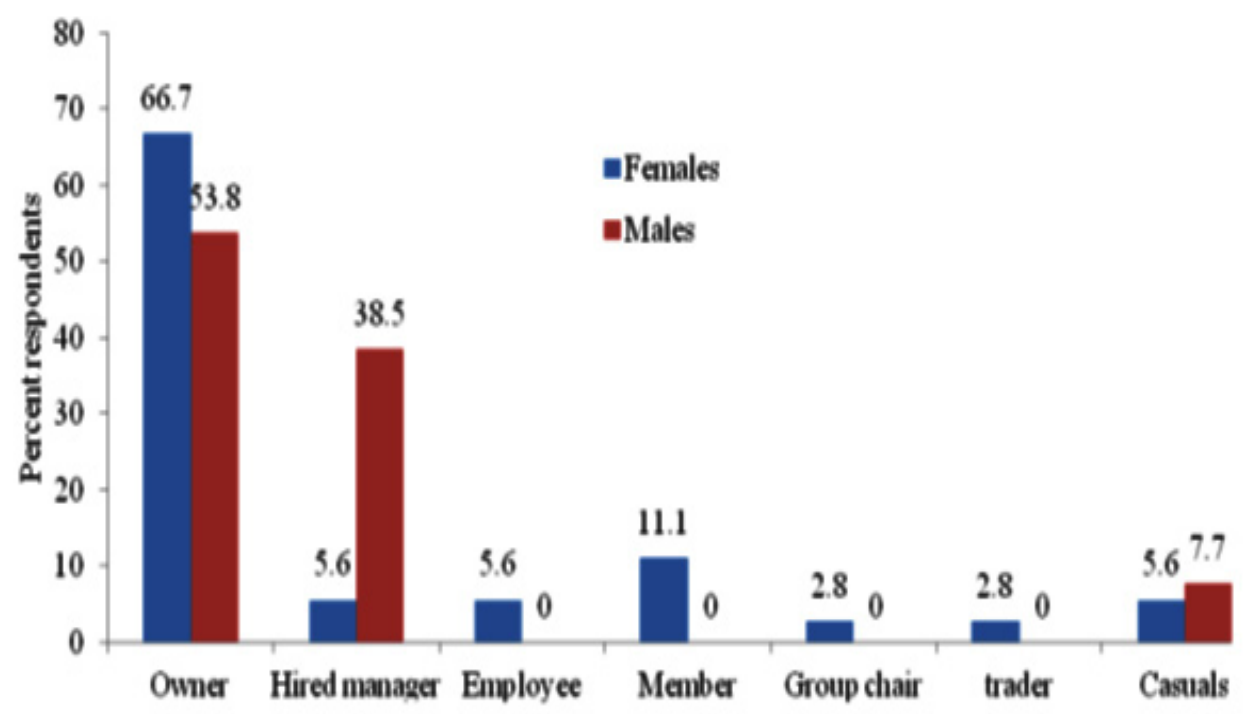

Fig. 3: Responsibility of cassava processors by gender in Coast, Migori and Busia of Kenya 
respectively. Most processors would therefore be considered as middle aged. However, most of the female processors were older compared to their male counterparts and their participation is all through the ages (Figure 2). When responsibility was considered by gender women participated in wider range of activities than men. Majority of processors are owners of the enterprises while hired managers and casuals were mainly men (Figure 3 ). It seems that men are more trusted to manage the business given their time availability. There was low level of casual laborers who accounted for only $8 \%$ of the respondents. This scenario indicates small-scale nature of cassava processors in Kenya.

The level of education was considerably low in the Coast as illustrated in Figure 4. About 13 $\%$ had no formal education while $42 \%$ had primary

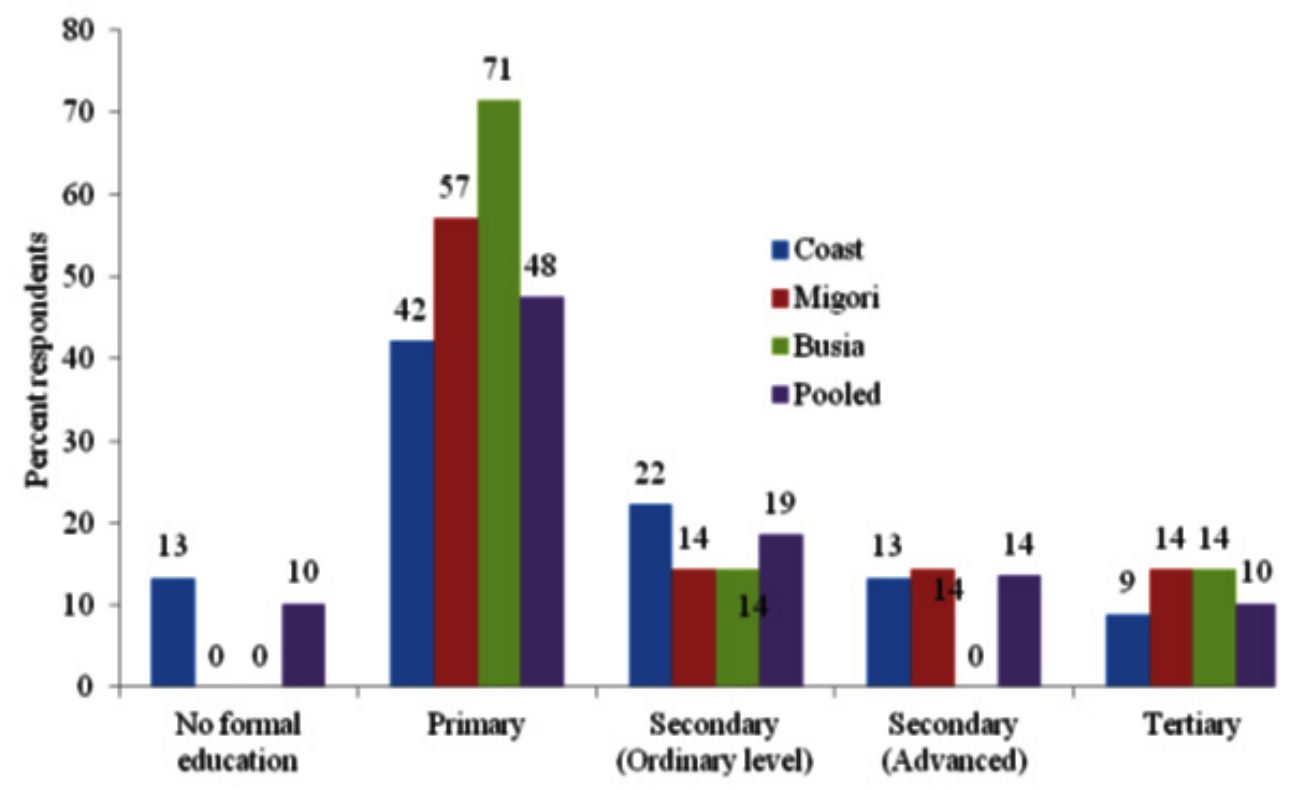

Fig. 4: Education profile for cassava processors in Coast, Migori and Busia of Kenya

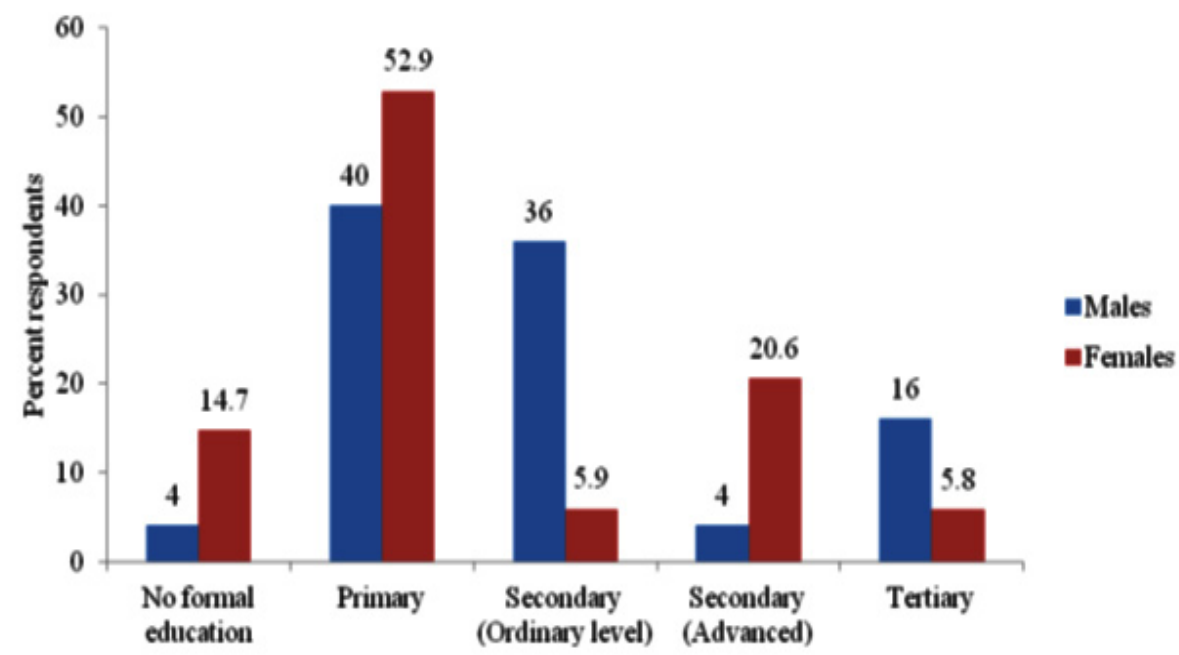

Fig. 5: Level of education by gender of cassava processors in Kenya 
education and only $9 \%$ had tertiary education. On the other hand, majority $(71 \%)$ of the respondents in Busia had primary education, $14 \%$ had secondary and tertiary level of education. In Migori, $57 \%$ had primary education while secondary and tertiary were $14 \%$ in each case. Women still participate in processing even at advance level of training compared to men. Education level determines in most cases the literacy level of any given society, and in most cases, the higher the level of education the higher the literacy level ${ }^{12}$. More females than males either had no formal, primary or secondary (advance) education while higher number of males

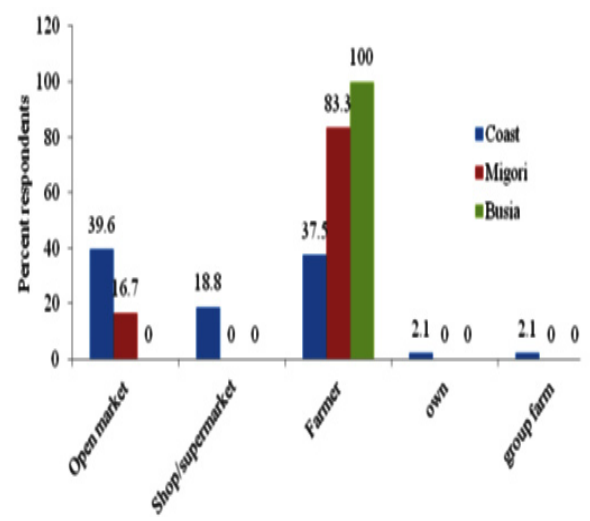

Fig. 6: Source of raw materials for cassava processing had secondary (ordinary) and tertiary education (Figure 5).

\section{Processing area and source of raw materials}

Most of the processing across the regions take place in open yards majority of these being in Busia (85 \%) followed by Migori (67\%) and Coast region $(57 \%)$. This may have great influence on the level of contamination depending on each region. Exposure of food products to open yard processing may lead to surface microbial contamination as well as foreign matter deposition onto the food material ${ }^{13}$. All processors from Busia relied on the farmers as a source of raw materials, compared to $83 \%$ in Migori and $37 \%$ in Coast (Figure 6). Fear of cyanide poisoning is a major deterrent of Busia and Migori processors from sourcing raw cassava among any other source away from farmers unlike Coast region where most varieties are known to be low in cyanide. Other sources are open market, group farms, shopsor super markets and own grown cassava.

The raw materials purchased by processors varied with the region with 74 and $67 \%$ of processors in the Coast and Busia respectively purchased their raw cassava. Migori processors mainly (67 $\%)$ purchased dried chips as their raw material compared to Coast (16\%) and Busia (33\%). Flour was only bought by Coast processors, mainly

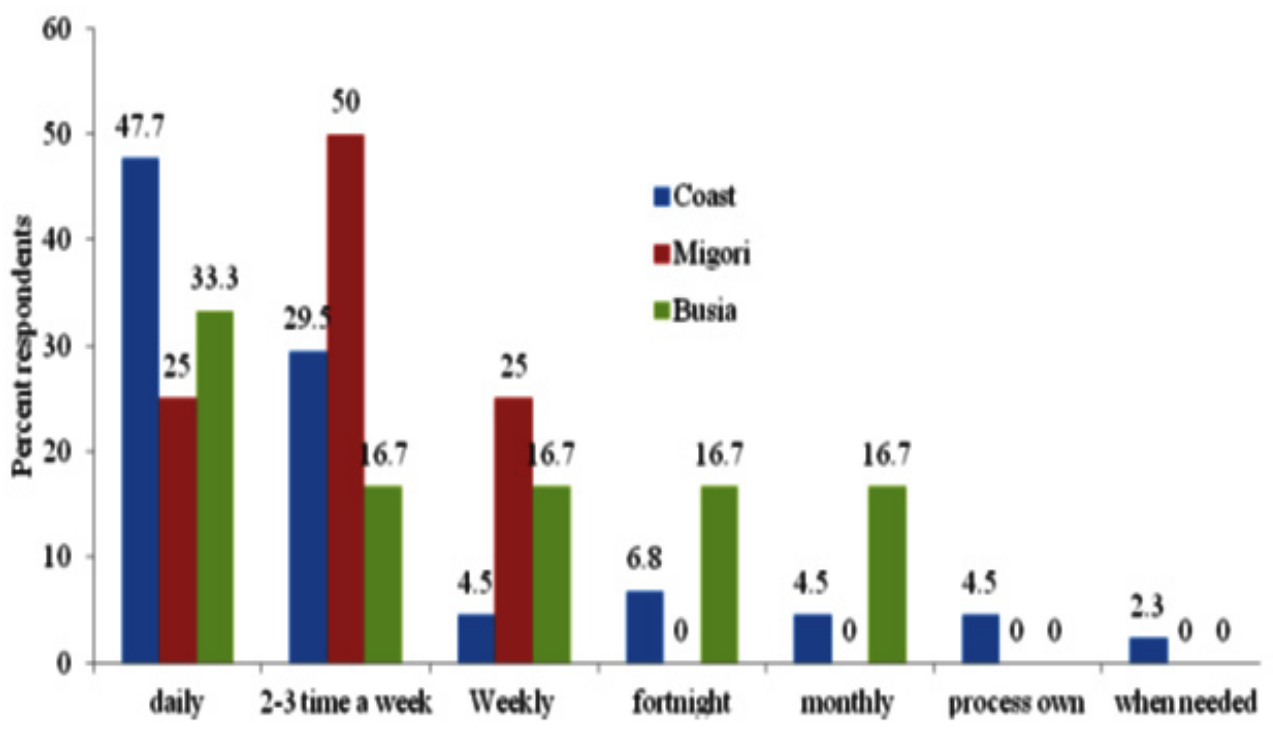

Fig. 7: Frequency of purchase of raw materials by processors 
meant for porridge preparations. The raw materials reflect the type of product produced by respective processors, more diversity from the Coast compared to the other regions. The frequency of raw materials purchase ranged from daily, 2-3 times a week and once a week in all the 3 regions (Figure 7). Majority of the Coast and Busia processors purchased the raw materials daily compared to Migori processors who mainly purchased 2-3times a week. This indicates the nature of processing across regions, mainly small scale and roots being highly perishable allow for bulk purchase.

\section{Processed cassava products}

Flour was the most common processed cassava product in the Coast (33\%) while dried chips was highly produced in Migori and Busia in equal proportion of $43 \%$ (Figure 8 ). Other important products are cassava crisps and composite flour. Coast region had a greater diversity of products which are none existent in other regions. This could be attributed to eating habits and cultural differences across the regions. Fear of cassava poisoning deters many people in Busia from use of fresh or boiled cassava, hence lack of it in markets as opposed to Coastal markets. Unlike in 2001 when Karuri and colleagues ${ }^{14}$ encountered sporadic starch processing, it was not the case in the current study. This indicates that cassava roots are very significant input for the processors and steps have to be taken to ensure safety as well as quality and adequate quantity of supply for improved products in the coast. Improving cassava chips and flour quality therefore remains an important challenge. Evaluation of

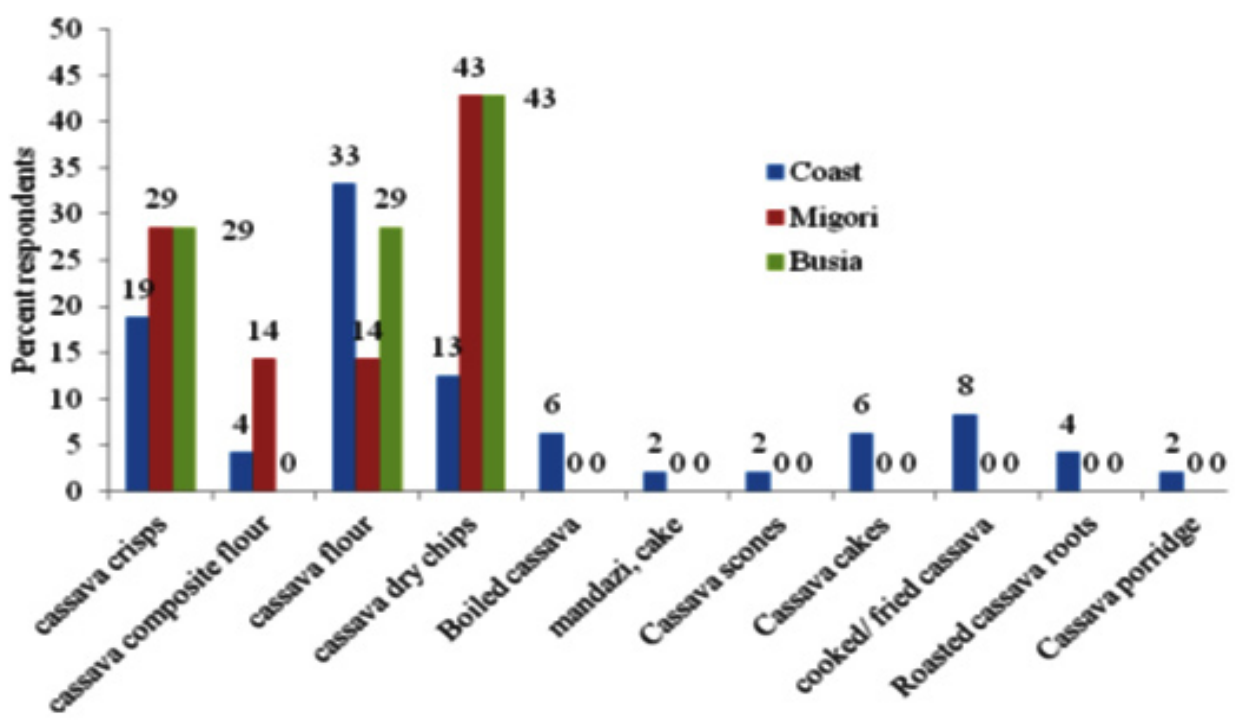

Fig. 8: Cassava processed products and quality aspects in Kenya

Table 1: Product markets (percent respondents) for cassava products

\begin{tabular}{lccc}
\hline Product markets & Coast & Migori & Busia \\
\hline Retailer & 11 & 0 & 17 \\
Final consumer & 64 & 33 & 50 \\
Both consumer & 26 & 67 & 0 \\
and retailer & & & \\
Millers & 0 & 0 & 33 \\
Total & 100 & 100 & 100 \\
\hline
\end{tabular}

Table 2: Demand (percent respondents) for cassava products

\begin{tabular}{lccc}
\hline Demand for products & Coast & Migori & Busia \\
\hline High demand & 51 & 67 & 57 \\
Average demand & 33 & 0 & 14 \\
Low demand & 16 & 33 & 29 \\
Total & 100 & 100 & 100 \\
\hline
\end{tabular}


current highly traded cassava flours remains critical towards its quality improvement. It is also important to note that the results are not weighted according to sample size per region. What is shown here are the proportions.
Over $50 \%$ of the processors sell their products to the final consumer in Busia and Coast as opposed to Migori processors who sell to both consumers and retailers (Table 1). This therefore eliminates brokers and other middlemen. This practice could also result from the fact that most

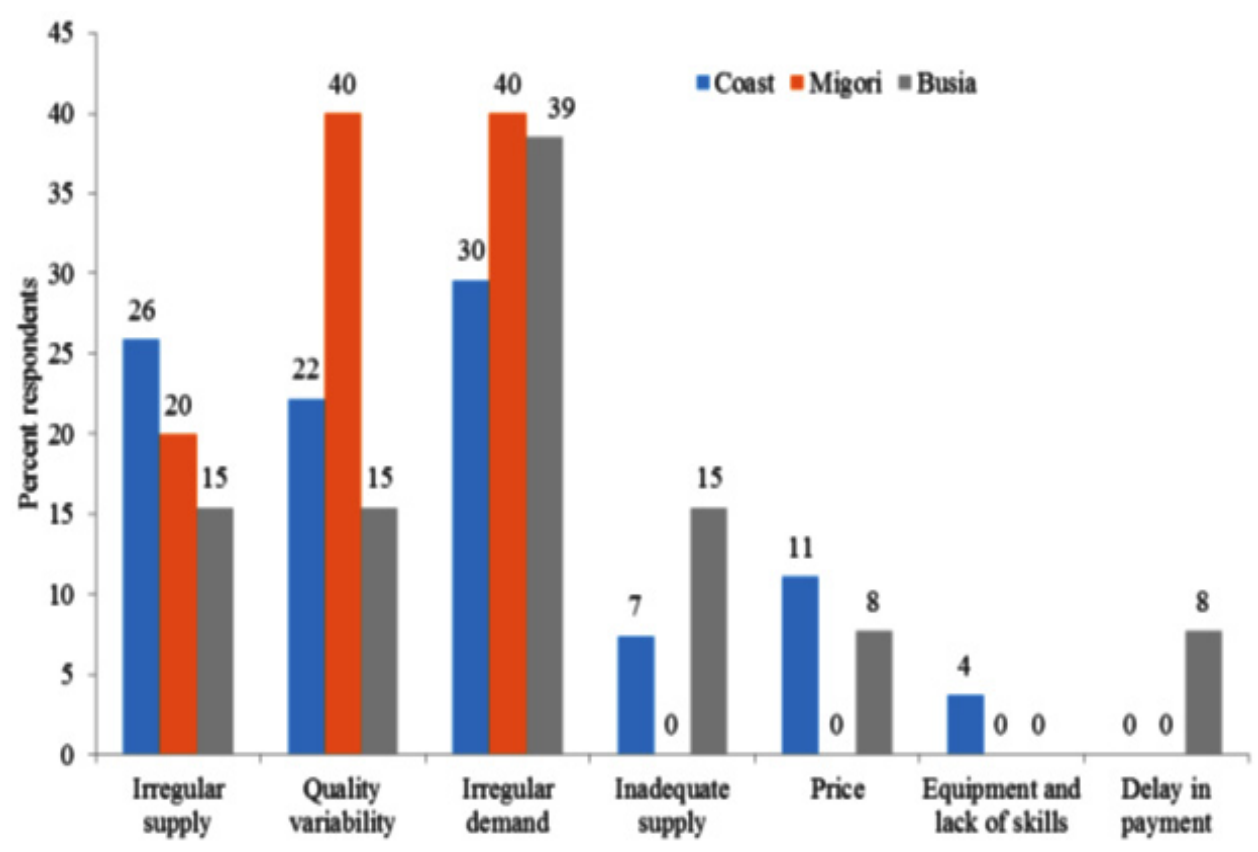

Fig. 9: Major problems faced by cassava processors

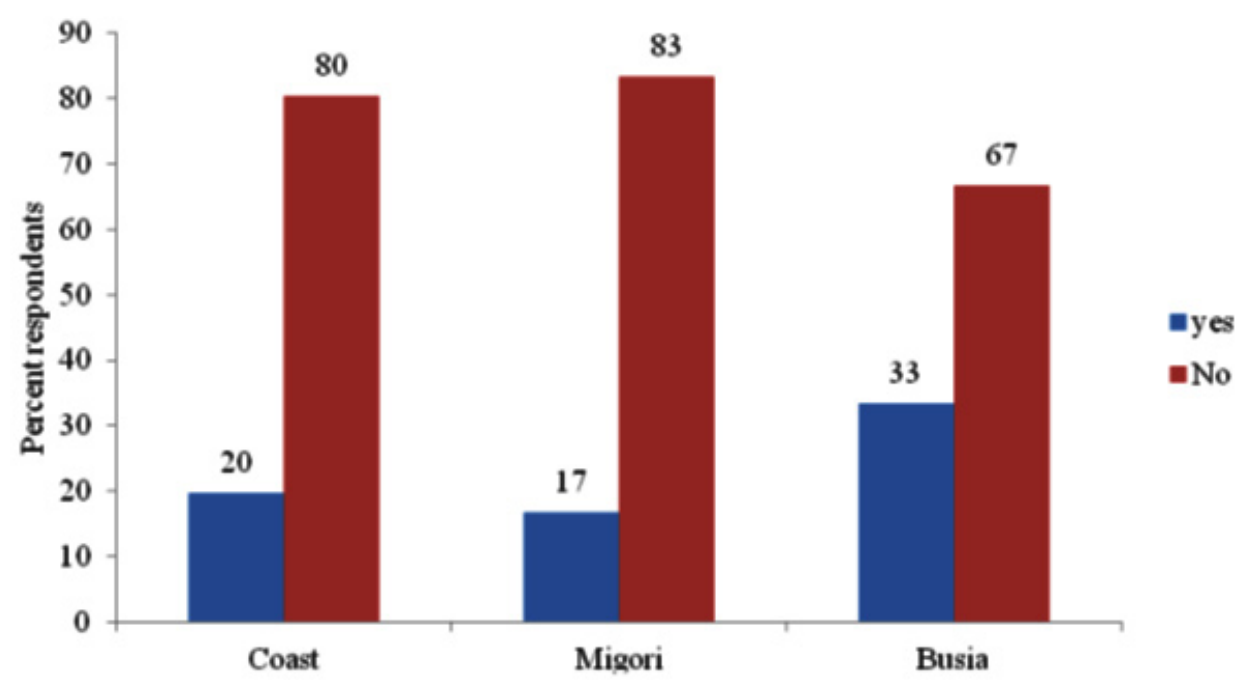

Fig. 10: Processors and affiliation to associations 
processors are retailers themselves. With the exception of Coast processors who relied heavily on Kibanda meno, most processors from Busia and Migori couldn't tell the variety of cassava they use for processing even though quality of the end products was noted as most important determinant for choosing specific variety they are used to. Product quality is usually variety specific ${ }^{15}$ and hence the need for adequate research and hence product specific breeding of cassava materials across Kenya. Individual products require given specifications which indeed require systematic evaluation rather than trial and era basis, as is the current practice.

\section{Marketing of cassava products}

The demand for cassava processed products was rated to be quite high across the regions with $51 \%$ in Coast, $67 \%$ in Migori and $57 \%$ in Busia (Table 2). Migori region only had two extremes of either high or low demand unlike Busia and Coast where average demand was also noted. About $70 \%$ of the processors from the Coast affirmed that the supply of cassava processed products was adequate

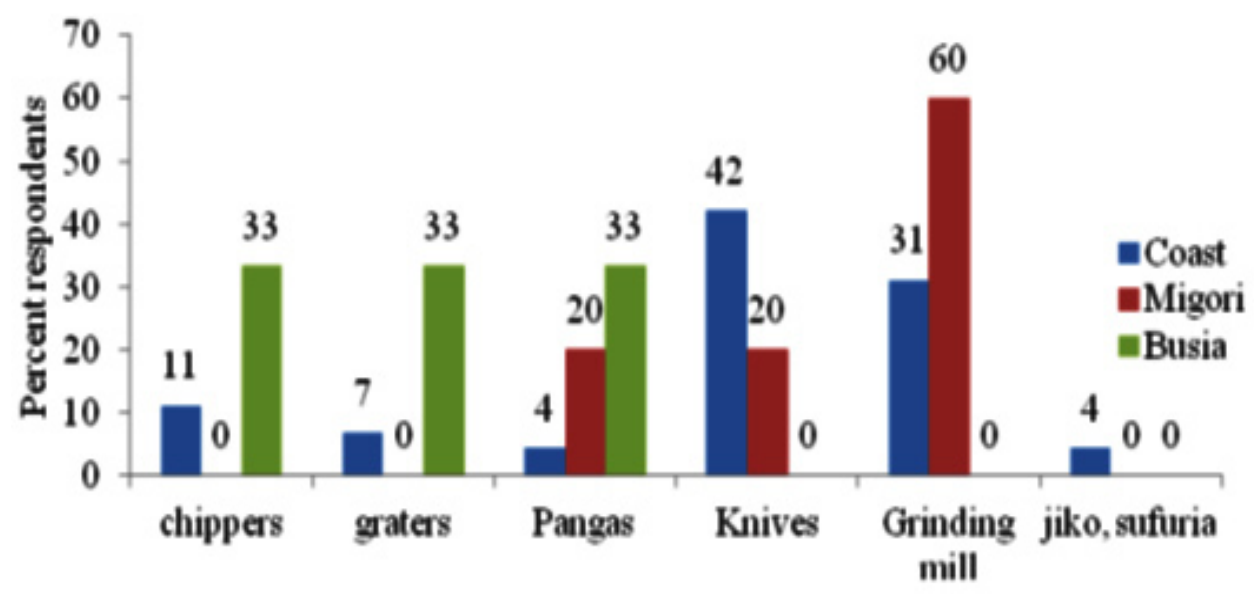

Fig. 11: Equipment used in processing cassava products in Kenya

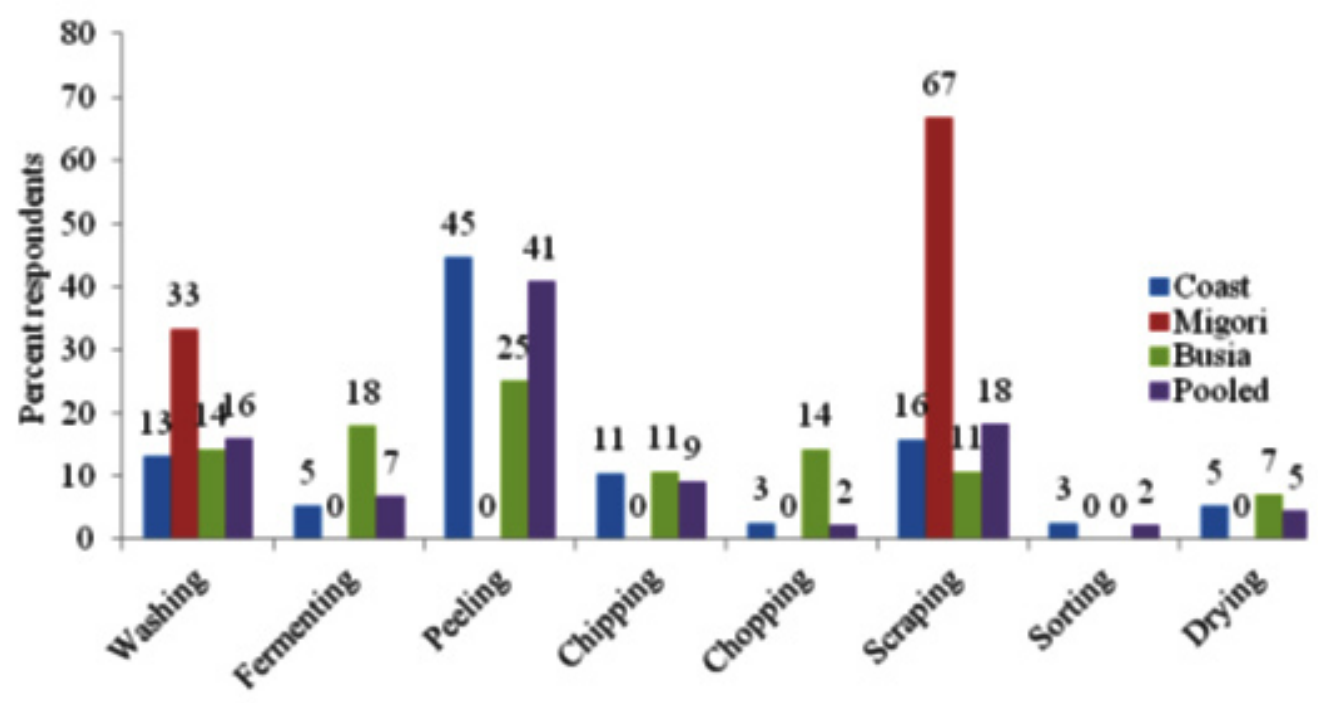

Fig. 12: Most common treatment methods during cassava processing 
to meet the customer demand throughout the year, while it was inadequate in Migori (57\%) and Busia $(60 \%)$. Majority of processors (70\%) from Coast did not make any contractual agreement with suppliers, only $23 \%$ made formal agreements. In Migori, $83 \%$ did not have any agreement compared to the $17 \%$ who did so. In Busia, equal number of processors fell in the two categories. Of those who made contractual agreement, $95 \%$ were informal. About $60 \%$ affirmed that they process cassava products by order with cassava sales being highest in August and lowest in the months of January that coincides with months of food sufficiency and insufficiency, respectively. The demand for cassava products may therefore not support continuous processing. Generally, majority $(70 \%)$ of processors do not carry out any marketing promotion. However, some of services are offered by the processors to attract more customers included credit services, suppliers' product delivery, free samples, and offering good quality services. Free samples comprised majority of the promotion services.

\section{Product characteristics and constraints}

The characteristics of importance for various cassava products during processing were stated as colour, taste, texture and storability depending on the product. Crisps for, instance, were being measured against colour, taste and storability, while flours would be considered based on storability, colour and existence of any foreign matter. Several problems were noted among processors whenever they went about daily operations in all regions. As a matter of fact $60 \%$ of the processors affirmed that they faced a number of problems (Figure 9). Major

Table 3: Reasons for the different treatments
(percent respondents) cassava is subjected to
during processing

Reasons for Coast Migori Busia Pooled
treatments

\begin{tabular}{lcccc}
\hline Cleaning & 16 & 0 & 24 & 21 \\
Detoxify & 8 & 33 & 28 & 9 \\
Reduce bulkiness & 8 & 33 & 16 & 9 \\
$\begin{array}{l}\text { Ease of further } \\
\text { processing }\end{array}$ & 60 & 33 & 16 & 54 \\
Better taste & 8 & 0 & 16 & 7 \\
Total & 100 & 100 & 100 & 100 \\
\hline
\end{tabular}

problems listed include irregular supply, quality variability and irregular demand.

Some of the suggested means to improve cassava processing include increasing supply of cassava roots, making solar driers available and accessible, improvement of cassava processing technology and infrastructure, promotion, group processing of cassava roots, improvement of the quality of cassava roots and thus processed products. Others include increasing cultivation of cassava by farmers, provision of extension services to farmers and processors and making loans more affordable. A few of the problems can be tackled with proper research as well as linkages with commercial institutions. A number of the limitations will, however, require concerted efforts by all stakeholders and especially through government intervention through tailored policies to streamline the sector.

\section{Processors and associations}

Despite the fact that $66 \%$ of the respondents do not belong to any processor association for business or welfare development (Figure 10), most $(81 \%)$ of the processors affirmed their willingness to work with other chain actors to improve the cassava processing. Through this interaction it can be expected that horizontal and vertical exchange of knowledge can be shared with ease. This indicates that there may be little economic interaction

Table 4: Major constraints faced by processors

\begin{tabular}{lccc}
\hline Constraints & Coast & Busia & Migori \\
\hline Inaccessibility & 25 & 0 & 0 \\
Rust & 14 & 0 & 0 \\
Breakdown & 8 & 0 & 20 \\
Injuries & 19 & 0 & 0 \\
Bluntness & 14 & 55 & 0 \\
Slow & 8 & 9 & 40 \\
Unimproved & 6 & 0 & 0 \\
equipment & & & \\
Costs of processing, & 6 & 0 & 0 \\
equipment & & & \\
Not available & 0 & 9 & 0 \\
Poor milling & 0 & 18 & 0 \\
Tedious & 0 & 9 & 0 \\
Fuel shortage & 0 & 0 & 40 \\
Total & 100 & 100 & 100 \\
\hline
\end{tabular}


between different processors and hence limiting them from accessing services that come with such associations. These benefits could be in form of loans, and subsidized prices on inputs. Those who belonged to business associations stated that their main activities include participation in farming, processing cakes and scones for income generation and education, and granting loans.

\section{Processing equipment and processing methods}

The most commonly used processing tools for roots processing are chippers, graters, pangas, knives and grinding mill across the regions. Jiko and sufuria were also used in the Coast, especially for boiled cassava (Figure 11). The tools used depended on the major product (s) in the given area, for instance, lots of respondents used knives and sufuria in the Coast since a large percentage of people process raw cassava into boiled and other products, while in Busia and Migori pangas and grinding mills were indicative of chips and flour highly processed in the regions. Chippers and graters were only used in the Coast and Busia.

Some of the treatments of cassava roots during processing include washing, fermenting, and peeling, chipping, chopping, scraping, sorting and

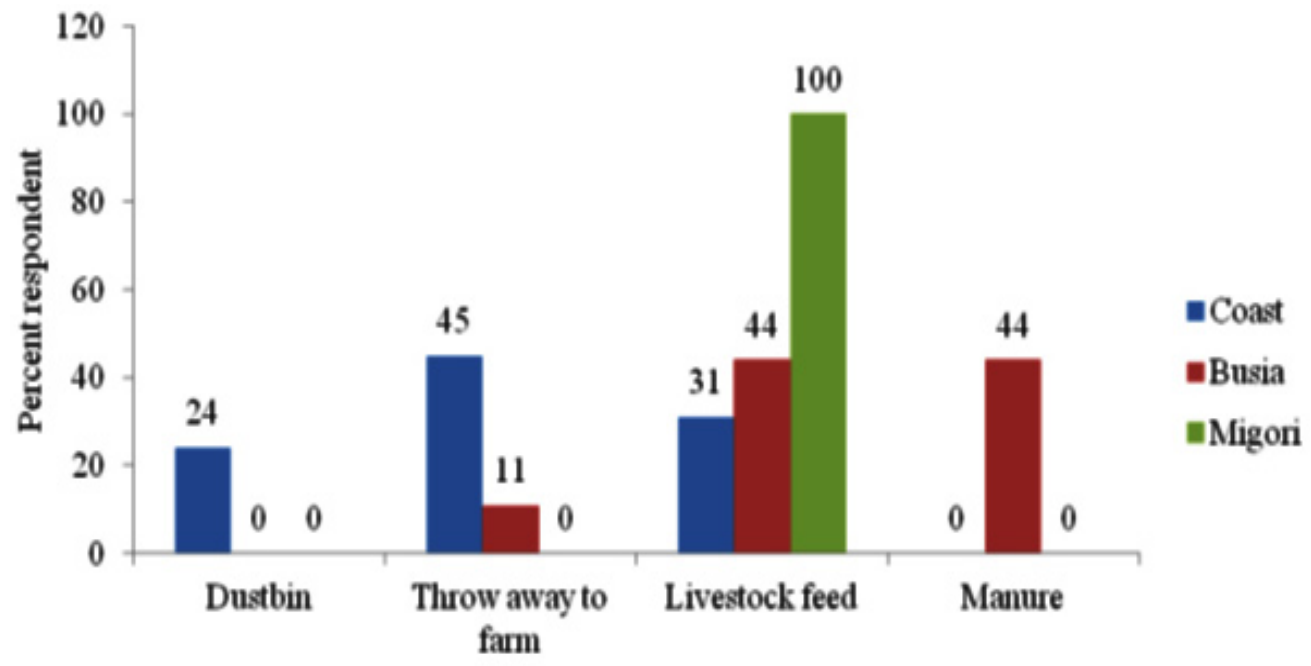

Mode of disposal

Fig. 13: Means of managing wastes by processors

Table 3.5: Cassava products packaging materials

Packaging Coast Migori Busia Pooled
materials

\begin{tabular}{lcccc}
\hline $\begin{array}{l}\text { Poly propylene } \\
\text { bags }\end{array}$ & 42 & 0 & 22 & 35 \\
Baskets & 0 & 25 & 0 & 3 \\
Gunny bags & 29 & 50 & 22 & 32 \\
Jute Bags & 3 & 0 & 33 & 3 \\
Drums & 3 & 0 & 0 & 3 \\
Plastic containers & 13 & 25 & 22 & 16 \\
Brown paper bags & 7 & 0 & 0 & 5 \\
Thermos flask & 3 & 0 & 0 & 3 \\
Total & 100 & 100 & 100 & 100 \\
\hline
\end{tabular}

drying (Figure 12). Most of the peeling takes place in the coast where fresh cassava is processed while washing and scraping is a common feature across the regions majority being in Migori. Washing is generally done on raw cassava to remove soil debris. Sorting is quite limited meaning that processors don't mind the product quality and any size preference. This may have negative impact on quality of final product especially where small highly fibrous roots are used in processing. Fermentation and drying which are preservation procedures account for a small proportion of the processes and the fact that sorting is very limited may mean inferior quality products are sold in the market. Fermentation was, however, high in Busia mainly because they are worried about cyanide poisoning. Reasons given 
for treatment of roots as indicated include cleaning, detoxification, reduce bulkiness, ease further processig and better taste-easing further processing being most important in each region (Table 3 ).

Some of the constraints faced in processing cassava and cassava products include inaccessibility, rusting equipment, breakdown, injuries, bluntness, dusty premises, foreign materials, tedious unimproved equipment and high cost of processing equipment (Table 4). Inaccessibility and injuries account for majority of the constraints. Some of the coping mechanisms to overcome the constraints include borrowing, sharpening the knives and blunt tools, repair and maintenance.

\section{Waste management in processing premises}

Most processors (45\%) across the regions throw away cassava wastes, while a small portion of in Coast use them as feeds. The rest are collected in dustbins (Figure 13). The former indicates the underutilization of cassava peels. Wastes can find use in production of value added products such as ethanol as well as animal feeds. Only $2 \%$ of processors use waste water from washing for irrigation. The rest is drained off. On the other hand, spoilt cassava products are fed to animals in Busia
(100\%), thrown away (85\%) or fed to pigs (15\%) in Coast, fed to chicken (50\%) or donated or thrown away (25\%) in Migori (25\%). Depending on the nature of damages and quantities, cassava products can be potential hazards especially where aflatoxin carrying products are donated or fed to animals. Proper disposal methods should be adopted after careful analysis of the damages.

\section{Packaging and storage of cassava and cassava products}

A large number ( $>64 \%$ ) of processors affirmed that they store cassava processed products. The reasons for storage included selling in a distant market, build up stock, to use later or due to inadequate demand. The primary reason being building up stock which is represented by $58 \%$ of the responses. About $63 \%$ of those who do not store their products quoted lack of appropriate storage facilities as the main reason for not storing them while $19 \%$ stated that they processed just enough for daily sale. Research in cheap storage facilities made of local materials is therefore of necessity especially given the fact that the storage material impact seriously on quality and safety of cassava products $^{16}$.

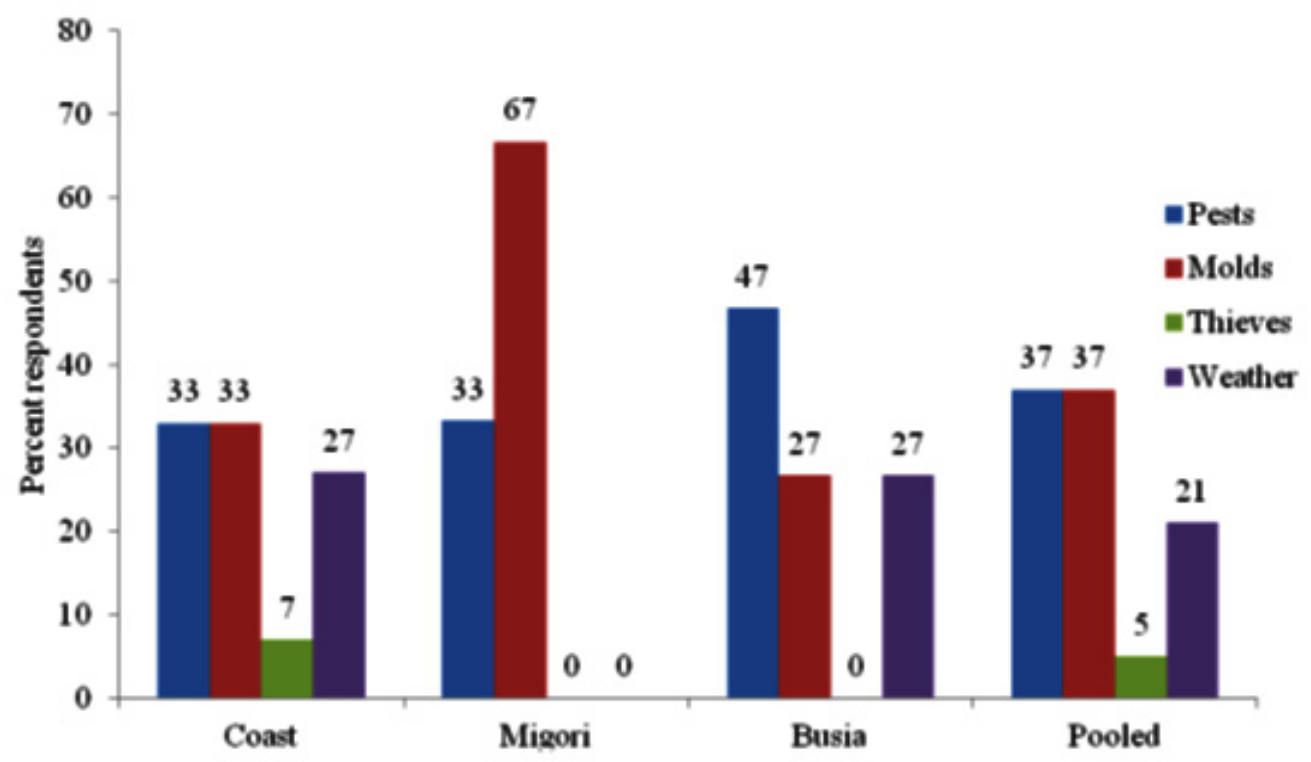

Fig.14: Major causes of losses in stored cassava products 
About $49 \%$ of the processors affirmed that they store cassava in the same store with other commodities. Cereals at $25 \%$ accounted for the highest proportion of these products; pests attacking this group will probably infest cassava products in the same store. Others include legumes, bananas, and cooked food. Some of the materials used to package products for storage include polypropylene bags, gunny bags, jute bags, drums, plastic containers, brown paper bags and thermos flasks (Table 5). The former two are the most popular accounting for $27 \%$ and $18 \%$ of the packages. About $25 \%$ of the respondents store their products on racks while $20 \%$ store them on shelves. Others include boxes, plastic drums and sachets. Convenience for sale was indicated as the major reason $(27 \%)$ for choosing particular packaging material, especially when it comes to sales of cassava flour. Others (22 $\%)$ sighted damage prevention, while the rest (8\%) sighted cost, cleanliness and aeration. Storage period of products before sale varies between $2 \mathrm{hrs}$ to more than a month depending on the product. Pests and molds account for majority (44\%) causes of losses encountered in cassava products (Figure 14).

About $26 \%$ of the respondents use the damaged products as feeds while the rest just discarded them. In conclusion, many processors decried lack of capacity building and training to enable them process high quality product that would lead to increased demand. At the same time, they require to easily access processing equipment e.g. chippers and millers as well as improvement of cassava farming methods, increased production of cassava to ensure it meets the demand throughout the year while creating more awareness on consumption of cassava products.

\section{CONCLUSION}

Cassava products are important for food security and add variety to the menu of many consumers. There exists challenges in processing, storage and handling of cassava and its products. Capacity building and training as concerns value addition, cassava storage and preservation should be considered by both researchers and government agencies directly associated with cassava traders and processors. Increased efforts on adult education may be considered by the government to improve literacy in the current study area.

\section{ACKNOWLEDGEMENT}

Funds for this study were provided by the World Bank through Eastern African Productivity Project (EAAPP). We acknowledge prudent management of the funds and leadership of Kenya Agricultural and Livestock Research Organization. Various farmer and community groups in Coast, Busia and Migori Counties that made this research easier and possible are highly appreciated.

\section{REFERENCES}

1. Hahn, S.K. and Keyser, J. Cassava: a basic food of Africa. Outlook on Agriculture; 14(2) 95-99: 1985.

2. Mushimiyimana I., Hakizimana E., Gashaka G., Sallah P.Y.K., Kalisa S., Gatunzi F., Asiimwe T., Kahia J., Gahakwa D. Micro-propagation of a disease resistant cassava variety in Rwanda. Rwanda Journal, Agricultural Sciences; 24:49-57: 2011.

3. Ferris, R.S. B., G. Ntibarikure, S. Kolijn and A.K. Muganga,. Developing value-added markets for cassava in East and Southern Africa. In: M.O. Akoroda and J.M. Ngeve (Eds.), Proceedings of the $7^{\text {th }}$ Triennial
Symposium of the International Society for Tropical Root crops- Africa branch (ISTRC), pp 667-681: 2001.

4. Government of Kenya (GOK). Sessional Paper No. 2 of 1996 on Industrial transformation to the Year 2020. Government Printer, Nairobi, Kenya. 1996.

5. Achacha, J. O. Post-Harvest Training Course on Processing and utilization of cassava in western Kenya. KARI Publication, Nairobi, Kenya: 2001.

6. Keya, E.L and Wanjekeche E. Effect of pulp processing variables on cassava and sweet potato cakes quality. The Journal of Food 
Technology in Africa; 2 (2): 44 -49: 1997.

7. Makokha A.O. Opportunities and constraints in commercialization of cassava production and processing in Kenya. In: M.O. Akoroda and J.M. Ngeve (Eds.), Proceedings of the $7^{\text {th }}$ Triennial Symposium of the International Society for Tropical Root crops- Africa branch (ISTRC), 121-125: 2001.

8. Onyango A. C.. Physico-chemical, sensory and keeping quality of cassava flour produced by simple drying techniques. Msc. Thesis. University of Nairobi: 1990.

9. Infante Evaluation of cassava plants generated by somatic embryogenesis at different stages of development using molecular markers. Electronic Journal of Biotechnology ISSN Print: 0717-3458- accessed on $2^{\text {nd }}$ November 2014: 2013

10. FAO/WHO. Joint FAO/WHO Food standards programme. Codex Alimentarius Commisiion XII, Supplement 4, FAO, Rome, Italy. 1991.

11. Government of Kenya (GoK). National Root and Tuber Crops Policy. Ministry of Agriculture, Nairobi Kenya: 2010.

12. Kilele, A.K.M. Adult Literacy in Kenya. Kenya National Bureau of Statistics. Accessed on $13^{\text {th }}$ November 2013 at http://www.knbs.or.ke/
downloads/pdf/KNALS2007.pdf: 2007.

13. Schlegelová, J., Babák, B., Holasová, M., Kons tantinová, L., Necidová, L., Šišák, F., VIková, N., Roubal P. and JaglicZ. Microbial Contamination after Sanitation of Food Contact Surfaces in Dairy and Meat Processing Plants. Czech J. Food Sci. 28(5): 450-461: 2010.

14. Karuri, E.G., Mbugua S.K., Karugia, J., Wanda, $\mathrm{K}$. and Jagwe, J. Marketing Opportunities for cassava based products: An Assessment of the Industrial Potential in Kenya. Accessed on $12^{\text {th }}$ November 2013 at http//:www.foodnet. cgiar.org/Projects/Fnetrep3.htm: 2001.

15. Montagnac, J.A., Davis, C.R and Tanumihard, S.A. Nutritional value of cassava for use as a staple food and recent advances for improvement. Comprehensive Reviews in Food Science and Food Safety, 8(3): 181-194: 2009.

16. Kaaya, A.N. and Eboku, D. Mould and Aflatoxin Contamination of Dried Cassava Chips in Eastern Uganda: Association with Traditional Processing and Storage Practices. Journal of Biological Sciences; 10: 718-729: 2010. 